\section{JURNAL EKONOMI EFEKTIF}

ISSN : $2622-8882$, E-ISSN : 2622-9935

Jurnal Ekonomi Efektif, Vol. 3, No. 4, Juli 2021 @Prodi Manajemen Fakultas Ekonomi Universitas Pamulang

\title{
PENGARUH MOTIVASI KERJA DAN LINGKUNGAN KERJA TERHADAP PRESTASI KERJA KARYAWAN PADA PT. SCREENPLAY PRODUCTIONS DI JAKARTA PUSAT
}

\author{
Edian Fahmy ${ }^{1 *}$, Theobaldus Boro Tura², Sri Sukapti ${ }^{3}$ \\ Universitas Pamulang, Tangerang Selatan, Banten, Indonesia \\ dosen01179@unpam.ac.id*
}

Manuskrip: Mei -2021 Ditinjau: Juni -2021; Diterima: Juni-2021; Online: Juli-2021; Diterbitkan: Juli-2021

\begin{abstract}
ABSTRAK
Penelitian ini bertujuan untuk mengetahui pengaruh motivasi kerja dan lingkungan kerja terhadap prestasi kerja karyawan pada PT. Screenplay Productions di Jakarta Pusat. Metode yang digunakan adalah explanatory research dengan teknik analisis menggunakan analisis statistik dengan pengujian regresi, korelasi, determinasi dan uji hipotesis. Hasil penelitian ini motivasi kerja berpengaruh signifikan terhadap prestasi kerja karyawan sebesar $42,1 \%$, uji hipotesis diperoleh $\mathrm{t}$ hitung $>\mathrm{t}$ tabel atau $(8,824>1,982)$. Lingkungan kerja berpengaruh signifikan terhadap prestasi kerja karyawan sebesar 38,5\%, uji hipotesis diperoleh thitung > t tabel atau $(8,129>1,982)$. Motivasi kerja dan lingkungan kerja secara simultan berpengaruh signifikan terhadap prestasi kerja karyawan dengan persamaan regresi $\mathrm{Y}=9,403+0,403 \mathrm{X} 1+$ $0,368 X 2$ dan kontribusi pengaruh sebesar 51,8\%, uji hipotesis diperoleh $\mathrm{F}$ hitung $>\mathrm{F}$ tabel atau $(56,861>1,690)$.
\end{abstract}

Kata Kunci: Motivasi Kerja, Lingkungan Kerja, Prestasi Kerja Karyawan

\begin{abstract}
This study aims to determine the effect of work motivation and work environment on employee performance at PT. Screenplay Productions in Central Jakarta. The method used is explanatory research with analytical techniques using statistical analysis with regression, correlation, determination and hypothesis testing. The results of this study that work motivation has a significant effect on employee performance by $42.1 \%$, hypothesis testing is obtained $t$ count > t table or $(8.824>1.982)$. The work environment has a significant effect on employee performance by 38.5\%, hypothesis testing is obtained t count > t table or (8,129 > 1,982). Work motivation and work environment simultaneously have a significant effect on employee performance with the regression equation $Y=9.403+0.403 X 1+0.368 X 2$ and the contribution of the influence is $51.8 \%$, hypothesis testing is obtained $F$ count $>F$ table or $(56.861>1.690)$.
\end{abstract}

Keywords: Work Motivation, Work Environment, Employee Performance 


\section{PENDAHULUAN}

\section{A. Latar Belakang}

Pemilihan sumber daya manusia yang berkualitas sangat diperlukan oleh setiap perusahaan. Semakin berkembang sebuah perusahaan maka semakin besar pula sumber daya manusia yang akan dibutuhkannya, maka akan semakin membutuhkan usaha yang lebih untuk dapat mengelolanya. Oleh karena itu, diperlukan adanya manajemen SDM perusahaan yang berfungsi untuk bisa menjaga keseimbangan dan mampu dalam memanfaatkannya produktivitas perusahaan.

Dalam manajemen SDM skill tertentu yang paling dibutuhkan perusahaan tidak bisa disangkal lagi bahwa semakin hari, maka jumlah sumber daya manusia akan semakin bertambah banyak. Namun, hanya beberapa diantaranya saja dari mereka yang benar-benar memiliki skill yang sesuai dengan kriteria yang banyak dibutuhkan oleh perusahaan. Beberapa perusahaan memerlukan SDM yang benar-benar memiliki skill khusus demi kemajuan bisnisnya, yang mana jumlah tersebut sangatlah terbatas. Hal ini akan semakin membuat perusahaan harus bersaing dengan perusahaan lain yang sejenis demi mendapatkan SDM tersebut.

Pengembangan sumber daya manusia tetap mampu dalam menjawab berbagai kebutuhan dari para konsumen dari hari ke hari, maka perusahaan juga harus berkembang agar tetap dapat bersaing dengan perusahaan-perusahaan lain yang sejenis. Manajemen SDM sebenarnya bisa dilakukan dengan cara meningkatkan skill tertentu atau membuat mereka mempelajari hal baru sehingga akan semakin mampu untuk menjadi pribadi yang serba multitalenta yang selalu siap sedia kapanpun perusahaan membutuhkannya, misalnya saja, dengan cara mewajibkan SDM untuk memiliki soft skill dalam berkomunikasi dengan para klien.

Seorang pemimpin harus bisa melakukan apa saja termasuk memotivasi para karyawan agar giat dalam bekerja dan mengerjakan tugas yang emban. Menurut Siagian (2016:138) "Motivasi adalah daya pendorong yang mengakibatkan seseorang anggota organisasi mau dan rela untuk menggerakan kemampuan dalam membentuk keahlian dan waktunya untuk menyelenggarakan berbagai kegiatan yang menjadi tanggung jawab dan menunaikan kewajiban dalam rangka pencapaian tujuan dan berbagai sasaran oraganisasi yang telah ditentukan sebelumnya."

PT Screenplay Produksi adalah perusahaan yang bergerak pada dunia industri perfilman Indonesia sejak tahun 2010 dan memiliki 150 karyawan. PT Screenplay Produksi a.k.a Screenplay Productions selain memproduksi sinetron dan FTV, juga memproduksi Film Layar Lebar. Tercatat sudah menghasilkan 10 judul film dalam kurung waktu 3 tahun sejak tahun 2015.Berkembangnya kinerja perusahaan tak luput dari kinerja para karyawan yang sangat baik dan tingginya minat penonton Indonesia untuk kembali memikmati perfilaman Indonesia, hingga perusahaan mampu bersaing dan berprestasi dalam industry perfilman di Indonesia. Namun dibalik kesuksesan atau besarnya suatu perusahaan selalu ada masalah yang dihadapi oleh perusahaan baik dari internal maupun eksternal yang terkadang menghambat laju bergeraknya perusahaan, yang kali ini peneliti amati adalah dari segi internal perusahaan terlebih dari tingkat motivasi yang menurun.

Didalam perusahaan seorang pemimpin hendaknya bisa membimbing seluruh karyawan didalam sebuah perusahaan agar bisa termotivasi oleh perilaku pemimpinnya. Menurut Soedarmayanti (2016:258) Motivasi adalah suatu dorongan dari pimpinan yang diberikan kepada karyawan untuk mencapai tujuan organisasi.

Untuk melihat kondisi awal proses motivasi di PT. Screenplay Productions Jakarta Pusat, maka penulis melakukan pra survey motivasi terhadap 150 orang karyawan dan 
hasilnya dapat dilihat dari data sebagai berikut:

Tabel 1. Daftar Karyawan yang mendapat promosi kenaikan jabatan di PT. Screenplay productions Jakarta Pusat

\begin{tabular}{|c|c|c|c|}
\hline No & Tahun & Jumlah (Orang) & Jumlah Yang Naik Jabatan (Orang) \\
\hline 1 & 2018 & 150 & 6 \\
\hline 2 & 2019 & 150 & 5 \\
\hline 3 & 2020 & 150 & 4 \\
\hline
\end{tabular}

Sumber: PT. Screenplay Productions Jakarta Pusat, 2021

Dari data tabel di atas dapat disimpulkan bahwa terjadinya masalah pada tahun 2018 karyawan yang mendaptkan promosi jabatan dari 150 orang hanya 6 orang kandidat, selanjutnya pada tahun 2019 mengalami penurunan karyawan yang dipromosikan jabatannya dan pada tahun 2020 itu menjadi paling rendah karyawan yang dipromosikan jawabannya, maka dari itu tanggung jawab tugas yang diberikan masih kurang dan selain tanggung jawab juga ada masalah lagi mengenai tujuan karyawan bekerja yang sangat menurun di PT. Screenplay Production.

Didalam perusahaan tidak hanya untuk mengerjakan apa yang diberikan oleh para pemimpin perusahan. Pemimpin juga harus memberi lingkungan kerja yang nyaman dan asri agar para karyawan bisa produtif dalam mengerjakan tugas yang di berikan. Menurut Sedarmayanti (2011:2) menyatakan: "Lingkungan Kerja adalah keseluruhan alat perkakas dan bahan yang dihadapi, lingkungan sekitarnya dimana seseorang bekerja, metode kerjanya, serta pengaturan kerjanya baik sebagai perseorangan maupun sebagai kelompok".

Maka dapat disimpulkan bahwa lingkungan kerja merupakan segala sesuatu yang ada di sekitar karyawan pada saat bekerja, baik yang berbentuk fisik ataupun non fisik, langsung atau tidak langsung, yang dapat mempengaruhi dirinya dan pekerjaanya saat bekerja.

Dalam pemenuhan standar kelayakan tempat atau lingkungan kerja di PT.Screenplay Productions Jakarta Pusat terdapat masih banyak yang belum terpenuhi, seperti pengadaan air bersih, sirkulasi udara, dan penerangan. Juga terdapat sistem koordinas atau kerja sama antar operator yang belum maksimal. Berikut ini saya lampirkan tabel barang inventaris pompa stasioner tentang Lingkungan Kerja di PT. Screenplay Productions Jakarta Pusat.

Berdasarkan observasi awal penulis ditemukan beberapa masalah yang bersangkutan dengan motivasi kerja karyawan dengan data sebagai berikut :

Tabel 2. Tabel barang inventaris di PT. Screenplay productions Jakarta Pusat

\begin{tabular}{|c|c|c|c|c|}
\hline No & Nama Barang & $\begin{array}{c}\text { Jumlah Barang Yang } \\
\text { Diperlukan }\end{array}$ & $\begin{array}{c}\text { Jumlah Barang } \\
\text { Yang Tersedia }\end{array}$ & Keterangan \\
\hline 1 & Meja & 30 & 25 & Belum mencukupi \\
\hline 2 & Kursi & 100 & 80 & Belum mencukupi \\
\hline 3 & Sofa & 10 & 7 & Belum mencukupi \\
\hline 4 & AC & 25 & 20 & Belum mencukupi \\
\hline
\end{tabular}

Sumber : PT. Screenplay Productions Jakarta Pusat, 2021

Berdasarkan tabel di atas menujukkan bahwa ada beberapa barang inventaris kantor yang masih belum mencukupi lingkungan kerja, dilihat barang-barang seperti meja belum mencukupi dari jumlah barang yang dibutuhkan 30 barang namun yang tersedia hanya 25 barang, kursi yang dibutuhkan sebanyak 100 barang namun tersedianya hanya 80 barang, sofa yang dibutuhkan sebanyak 10 barang namun tersedianya hanya 7 barang, dan AC yang dibutuhka sebanyak 15 barang namun tersedianya hanya 10 barang. Dengan masih adanya kekurangan dalam standar kelayakan pada sebuah lingkungan kerja, maka prestasi kerja mengalami penurunan, karena fasilitas yang ada tidak mendukung karyawan untuk bekerja secara maksimal. 
Dengan adanya faktor motivasi dan lingkungan kerja, maka prestasi kerja akan mengalami perubahan sesuai kedua faktor tersebut. Prestasi kerja karyawan merupakan salah satu indikator keberhasilan operasi perusahaan dalam mencapai suatu tujuan yang diingin perusahaan. Salah satu usaha yang tepat untuk dilakukan agar mereka mau berkerja dengan giat adalah dengan cara memberikan motivasi terhadap semua karyawan diperusahaan.

Menurut Bernardin dan Russel dikutip Sutrisno (2016:150) menyatakan: "Prestasi adalah catatan tentang hasil-hasil yang diperoleh dari fungsi-fungsi pekerjaan tertentu atau kegiatan tertentu selama kurun waktu tertentu.

Menurut Mangkunegara (2013:67) menyatakan: "Prestasi kerja adalah hasil kerja secara kualitas dan kuantitas yang dicapai oleh seseorang karyawan dalam melaksanakan tugasnya sesuai dengan tanggung jawab yang diberikan kepadanya.

Menurut Hasibuan (2016:94) menyatakan: "Prestasi kerja adalah suatu hasil kerja yang dicapai seseorang dalam melaksanakan tugas-tugas yang dibebankan kepadanya yang didasarkan atas kecakapan, pengalaman, dan kesuguhan serta waktu.

Pada dasarnya penilaian prestasi kerja dilaksanakan berdasarkan kesepakatan pelaksanaan suatu pekerjaan antara atasan dan stafnya, yang selanjutnya dimonitor dan disimpulkan selama masa penilaian berlangsung dan pengertian penilaian prestasi kerja merupakan usaha membandingkan antara hasil kerja yang dicapai oleh seorang karyawan dengan standar prestasi yang telah ditetapkan oleh perusahaan.Berdasarkan observasi awal penulis ditemukan beberapa masalah yang bersangkutan dengan motivasi kerja karyawan dengan data sebagai berikut :

Tabel 3. Tabel target jumlah penonton dari tahun 2018-2020 di PT. Screenplay Productions Jakarta Pusat

\begin{tabular}{|c|c|c|c|c|}
\hline No & Tahun & $\begin{array}{c}\text { Jumlah } \\
\text { Fil/tahun }\end{array}$ & Jumlah kota promosi film & Jumlah Penonton \\
\hline 1 & 2018 & 4 & 20 & 3.000 .000 \\
\hline 2 & 2019 & 4 & 20 & 2.800 .000 \\
\hline 3 & 2020 & 4 & 20 & 2.000 .000 \\
\hline
\end{tabular}

Sumber : PT. Screenplay Productions Jakarta Pusat, 2021

Berdasarkan data tabel di atas meunjukan bahwa ada penurunan jumlah pengunjung bioskop dari tahun 2018 sebanyak 3.000.000 pengunjung menjadi 2.000.000 pengunjung pada tahun 2020 jadi setiap tahunnya pengunjung mengalami penurunan kualitas pembelian tiket bioskop dan selain faktor tersebut juga terdapat faktor dari tanggung jawab para karyawan yang kurang dalam melakukan penjualan tiket bioskop.

Berdasarkan uraian di atas, maka penulis tertarik melakukan penelitian dengan judul: "Pengaruh Motivasi Kerja dan Lingkungan Kerja Terhadap Prestasi Kerja Karyawan Pada PT. Screenplay Productions, Jakarta Pusat".

\section{B. Rumusan Masalah}

1. Adakah pengaruh motivasi kerja terhadap prestasi kerja karyawan pada PT. Screenplay Productions di Jakarta Pusat?

2. Adakah pengaruh lingkungan kerja terhadap prestasi kerja karyawan pada PT. Screenplay Productions di Jakarta Pusat?

3. Adakah pengaruh secara simultan motivasi kerja dan lingkungan kerja terhadap prestasi kerja karyawan pada PT. Screenplay Productions di Jakarta Pusat ?

\section{Tujuan Penelitian}

1. Untuk mengetahui pengaruh motivasi kerja terhadap prestasi kerja karyawan pada PT. Screenplay Productions di Jakarta Pusat. 
2. Untuk mengetahui pengaruh lingkungan kerja terhadap prestasi kerja karyawan pada PT. Screenplay Productions di Jakarta Pusat.

3. Untuk mengetahui pengaruh secara simultan antara motivasi kerja dan lingkungan kerja terhadap prestasi kerja karyawan pada PT. Screenplay Productions di Jakarta Pusat.

\section{TINJAUAN PUSTAKA}

\section{Motivasi Kerja}

Motivasi kerja merupakan kondisi yang membuat karyawan mempunyai kemauan atau kebutuhan untuk mencapai tujuan tertentu melalui pelaksanaan suatu tugas. Motivasi kerja karyawan akan mensuplai energi untuk bekerja atau mengarahkan aktivitas selama bekerja, dan menyebabkan seorang karyawan mengetahui adanya tujuan yang relevan antara tujuan organisasi dengan tujuan pribadinya. Menurut Hasibuan (2015:23) pengertian motivasi adalah mempersoalkan bagaimana cara mendorong gairah kerja bawahan, agar mereka mau bekerja keras dengan memberikan semua kemampuan dan keterampilan untuk mewujudkan tujuan perusahaan

\section{Lingkungan Kerja}

Lingkungan kerja merupakan segala sesuatu yang ada di sekitar karyawan dan yang dapat mempngaruhi dirinya dalam menjalankan tugas-tugas yang di berikan kepadanya. Menurut Nitisemito (2010:197) Lingkungan kerja adalah segala sesuatu yang ada disekitar para pekerja dan yang dapat mempengaruhi dirinya dalam menjalankan tugastugas yang dibebankan. Misalnya kebersihan, musik dan sebagainya.

\section{Prestasi Kerja Karyawan}

Prestasi kerja merupakan hasil kerja seseorang karyawan selama priode tertentu dibandingkan dengan berbagai kemungkinan misalnya standard target/sasaran atau kriteria yang telah ditentukan terlebih dahulu dan disepakati bersama. Menurut Rivai (2011:274) menyatakan Prestasi kerja adalah proses melalui mana organisasi-organisasi mengevaluasi atau menilai prestasi kerja karyawan.

\section{METODE PENELITIAN}

\section{Populasi}

Populasi dalam penelitian ini berjumlah 109 responden Karyawan PT. Screenplay Productions di Jakarta Pusat

\section{Sampel}

Sampel dalam penelitian ini berjumlah 109 responden.

\section{Jenis Penelitian}

Jenis penelitian yang dipakai adalah kuantitatif, dimana tujuannya adalah untuk mengetahui pengaruh antara variabel bebas terhadap variabel terikat baik parsial maupun simultan

\section{Metode Analisis Data}

Dalam menganalisis data digunakan uji instrumen, uji asumsi klasik, regresi, koefisien korelasi, koefisien determinasi dan uji hipotesis.

\section{HASIL PENELITIAN}

\section{Analisis Deskriptif}

Pada pengujian ini digunakan untuk mengetahui skor minimum dan maksimum, mean score dan standar deviasi dari masing-masing variabel. Adapun hasilnya sebagai 
berikut:

Tabel 4. Hasil Analisis Descriptive Statistics

Descriptive Statistics

\begin{tabular}{|l|c|r|r|r|r|} 
& \multicolumn{9}{c}{ Descriptive Statistics } & & \\
& N & Minimum & Maximum & Mean & Std. Deviation \\
\hline Motivasi Kerja (X1) & 109 & 30 & 48 & 37.69 & 3.922 \\
\hline Lingkungan Kerja (X2) & 109 & 30 & 46 & 37.96 & 3.664 \\
\hline Prestasi Kerja Karyawan (Y) & 109 & 30 & 46 & 38.57 & 3.599 \\
\hline Valid N (listwise) & 109 & & & & \\
\hline
\end{tabular}

Motivasi kerja diperoleh varians minimum sebesar 30 dan varians maximum 48 dengan mean score sebesar 37,69 dengan standar deviasi 3,992.

Lingkungan kerja diperoleh varians minimum sebesar 30 dan varians maximum 46 dengan mean score sebesar 37,96 dengan standar deviasi 3,664.

Prestasi kerja karyawan diperoleh varians minimum sebesar 30 dan varians maximum 46 dengan mean score sebesar 38,57 dengan standar deviasi 3,599.

\section{Analisis Kuantitatif}

Pada analisis ini dimaksudkan untuk mengetahui pengaruh variabel independen terhadap variabel dependen. Adapun hasil pengujian sebagai berikut:

\section{a. Analisis Regresi Linier Berganda}

Uji regresi ini dimaksudkan untuk mengetahui perubahan variabel dependen jika variabel independen mengalami perubahan. Adapun hasil pengujiannya sebagai berikut:

Tabel 5. Hasil Pengujian Regresi Linier Berganda

\begin{tabular}{|c|c|c|c|c|c|c|}
\hline \multirow{3}{*}{\multicolumn{2}{|c|}{ Model }} & \multicolumn{2}{|c|}{ Coefficients ${ }^{a}$} & \multirow{2}{*}{$\begin{array}{l}\text { Standardized } \\
\text { Coefficients }\end{array}$} & \multirow[b]{3}{*}{$\mathrm{t}$} & \multirow[b]{3}{*}{ Sig. } \\
\hline & & \multicolumn{2}{|c|}{$\begin{array}{l}\text { Unstandardized } \\
\text { Coefficients }\end{array}$} & & & \\
\hline & & B & Std. Error & Beta & & \\
\hline 1 & (Constant) & 9.403 & 2.763 & & 3.403 & .001 \\
\hline & Motivasi Kerja (X1) & .403 & .075 & .440 & 5.403 & .000 \\
\hline & Lingkungan Kerja (X2) & .368 & .080 & .374 & 4.602 & .000 \\
\hline
\end{tabular}

a. Dependent Variable: Prestasi Kerja Karyawan (Y)

Berdasarkan hasil pengujian pada tabel di atas, diperoleh persamaan regresi $\mathrm{Y}$ $=9,403+0,403 X 1+0,368 X 2$. Dari persamaan tersebut dijelaskan sebagai berikut:

1) Konstanta sebesar 9,403 diartikan jika motivasi kerja dan lingkungan kerja tidak ada, maka telah terdapat nilai prestasi kerja karyawan sebesar 9,403 point.

2) Koefisien regresi motivasi kerja sebesar 0,403 , angka ini positif artinya setiap ada peningkatan motivasi kerja sebesar 0,403 maka prestasi kerja karyawan juga akan mengalami peningkatan sebesar 0,403 point.

3) Koefisien regresi lingkungan kerja sebesar 0,368, angka ini positif artinya setiap ada peningkatan lingkungan kerja sebesar 0,368 maka prestasi kerja karyawan juga akan mengalami peningkatan sebesar 0,368 point.

\section{b. Analisis Koefisien Korelasi}

Analisis koefisien korelasi dimaksudkan untuk mengetahui tingkt kekuatan hubungan dari variabel independen terhadap variabel dependen baik secara parsial maupun simultan. Adapun hasil pengujian sebagai berikut: 
Tabel 6. Hasil Pengujian Koefisien Korelasi Motivasi kerja Terhadap Prestasi kerja Karyawan. Correlations $^{\mathbf{b}}$

\begin{tabular}{llr|r} 
& & \multicolumn{1}{c}{$\begin{array}{c}\text { Motivasi } \\
\text { Kerja (X1) }\end{array}$} & $\begin{array}{r}\text { Prestasi Kerja } \\
\text { Karyawan (Y) }\end{array}$ \\
\hline Motivasi Kerja (X1) & Pearson Correlation & 1 & $.649^{* *}$ \\
\cline { 2 - 4 } & Sig. (2-tailed) & & .000 \\
\hline Prestasi Kerja Karyawan (Y) & Pearson Correlation & $.649^{* *}$ & 1 \\
\cline { 2 - 4 } & Sig. (2-tailed) & .000 & \\
\hline
\end{tabular}

**. Correlation is significant at the 0.01 level (2-tailed).

b. Listwise $\mathrm{N}=109$

Berdasarkan hasil pengujian diperoleh nilai korelasi sebesar 0,649 artinya motivasi kerja memiliki hubungan yang kuat terhadap prestasi kerja karyawan.

Tabel 7. Hasil Pengujian Koefisien Korelasi Lingkungan kerja Terhadap Prestasi kerja Karyawan. Correlations $^{\mathbf{b}}$

\begin{tabular}{llr|r} 
& \multicolumn{1}{c}{ Correlations $^{\mathbf{b}}$} & $\begin{array}{c}\text { Lingkungan } \\
\text { Kerja (X2) }\end{array}$ & $\begin{array}{r}\text { Prestasi Kerja } \\
\text { Karyawan (Y) }\end{array}$ \\
\hline Lingkungan Kerja (X2) & Pearson Correlation & 1 & $.620^{* *}$ \\
\cline { 2 - 4 } & Sig. (2-tailed) & .000 \\
\hline Prestasi Kerja Karyawan (Y) & Pearson Correlation & $.620^{* *}$ & 1 \\
\cline { 2 - 3 } & Sig. (2-tailed) & .000 & \\
\hline
\end{tabular}

**. Correlation is significant at the 0.01 level (2-tailed).

b. Listwise $\mathrm{N}=109$

Berdasarkan hasil pengujian diperoleh nilai korelasi sebesar 0,620 artinya lingkungan kerja memiliki hubungan yang kuat terhadap prestasi kerja karyawan.

Tabel 8. Hasil Pengujian Koefisien Korelasi Motivasi kerja dan Lingkungan kerja secara simultan Terhadap Prestasi kerja Karyawan.

Model Summary

\begin{tabular}{lr|r|r|r} 
& & \multicolumn{2}{c}{ Model Summary } & \multicolumn{2}{c}{$\begin{array}{c}\text { Adjusted R } \\
\text { Model }\end{array}$} & R & R Square & \multicolumn{1}{c}{$\begin{array}{c}\text { Std. Error of the } \\
\text { Estimate }\end{array}$} \\
\hline 1 & $.719^{\mathrm{a}}$ & .518 & .508 & 2.523 \\
\hline
\end{tabular}

a. Predictors: (Constant), Lingkungan Kerja (X2), Motivasi Kerja (X1)

Berdasarkan hasil pengujian diperoleh nilai korelasi sebesar 0,719 artinya motivasi kerja dan lingkungan kerja secara simultan memiliki hubungan yang kuat terhadap prestasi kerja karyawan.

\section{c. Analisis Koefisien Determinasi}

Analisis koefisien determinasi dimaksudkan untuk mengetahui besarnya persentase pengaruh dari variabel independen terhadap variabel dependen baik secara parsial maupun simultan. Adapun hasil pengujian sebagai berikut:

Tabel 9. Hasil Pengujian Koefisien Determinasi Motivasi kerja Terhadap Prestasi kerja Karyawan.

Model Summary

\begin{tabular}{|c|c|c|c|c|}
\hline \multicolumn{5}{|c|}{ Model Summary } \\
\hline Model & $\mathrm{R}$ & R Square & $\begin{array}{l}\text { Adjusted R } \\
\text { Square }\end{array}$ & $\begin{array}{l}\text { Std. Error of the } \\
\text { Estimate }\end{array}$ \\
\hline 1 & $.649^{\mathrm{a}}$ & .421 & .416 & 2.751 \\
\hline
\end{tabular}


Tabel 10. Hasil Pengujian Koefisien Determinasi Lingkungan kerja Terhadap Prestasi kerja Karyawan.

Model Summary

\begin{tabular}{|c|c|c|c|c|}
\hline \multicolumn{5}{|c|}{ 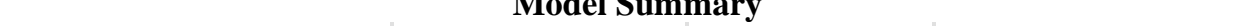 } \\
\hline Model & $\mathrm{R}$ & R Square & $\begin{array}{l}\text { Adjusted R } \\
\text { Square }\end{array}$ & $\begin{array}{l}\text { Std. Error of the } \\
\text { Estimate }\end{array}$ \\
\hline 1 & $.620^{\mathrm{a}}$ & .385 & .379 & 2.830 \\
\hline
\end{tabular}

a. Predictors: (Constant), Lingkungan Kerja (X2)

Berdasarkan hasil pengujian diperoleh nilai determinasi sebesar 0,385 artinya lingkungan kerja memiliki kontribusi pengaruh sebesar 38,5\% terhadap prestasi kerja karyawan.

Tabel 11. Hasil Pengujian Koefisien Determinasi Motivasi kerja dan Lingkungan kerja Terhadap Prestasi kerja Karyawan.

\begin{tabular}{l|c|c|c|cr} 
& \multicolumn{2}{c}{ Model Summary } \\
Model & $\mathrm{R}$ & R Square & Adjusted R & \multicolumn{2}{c}{$\begin{array}{c}\text { Std. Error of the } \\
\text { Square }\end{array}$} \\
\hline 1 & $.719^{\mathrm{a}}$ & .518 & .508 & 2.523 \\
\hline
\end{tabular}

a. Predictors: (Constant), Lingkungan Kerja (X2), Motivasi Kerja (X1)

Berdasarkan hasil pengujian diperoleh nilai determinasi sebesar 0,518 artinya motivasi kerja dan lingkungan kerja secara simultan memiliki kontribusi pengaruh sebesar $51,8 \%$ terhadap prestasi kerja karyawan, sedangkan sisanya sebesar 48,2\% dipengaruhi faktor lain.

\section{d. Uji Hipotesis}

\section{Uji hipotesis Parsial (Uji t)}

Pengujian hipotesis dengan uji t digunakan untuk mengetahui hipotesis parsial mana yang diterima.

Hipotesis pertama: Terdapat pengaruh yang signifikan antara motivasi kerja terhadap prestasi kerja karyawan.

Hipotesis kedua: Terdapat pengaruh yang signifikan antara lingkungan kerja terhadap prestasi kerja karyawan.

Tabel 12. Hasil Uji Hipotesis Motivasi kerja Terhadap Prestasi kerja Karyawan.

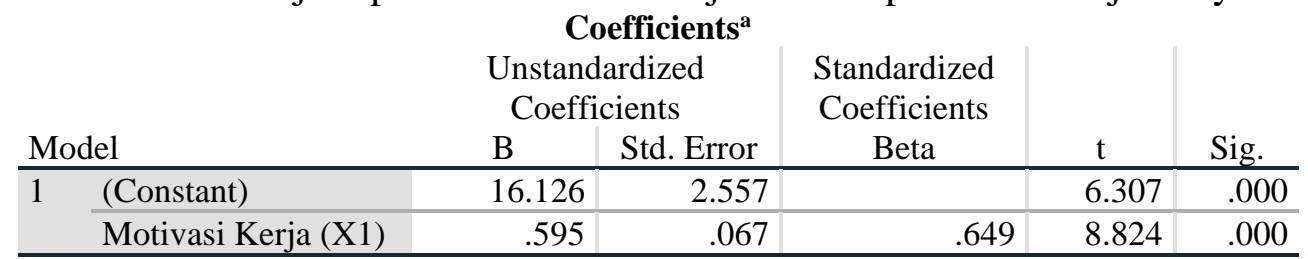

a. Dependent Variable: Prestasi Kerja Karyawan (Y)

Berdasarkan hasil pengujian pada tabel di atas, diperoleh nilai t hitung $>\mathrm{t}$ tabel atau $(8,824>1,982)$, dengan demikian hipotesis pertama yang diajukan bahwa terdapat pengaruh yang signifikan atara motivasi kerja terhadap prestasi kerja karyawan diterima.

Tabel 13. Hasil Uji Hipotesis Lingkungan kerja Terhadap Prestasi kerja Karyawan.

\begin{tabular}{|c|c|c|c|c|c|c|}
\hline \multirow{2}{*}{\multicolumn{2}{|c|}{ Model }} & $\begin{array}{r}\text { Co } \\
\text { Unsta } \\
\text { Coe }\end{array}$ & $\begin{array}{l}\text { ficients }^{\mathrm{a}} \\
\text { dardized } \\
\text { icients }\end{array}$ & \multirow{2}{*}{$\begin{array}{c}\text { Standardized } \\
\text { Coefficients } \\
\text { Beta }\end{array}$} & \multirow[b]{2}{*}{$\mathrm{t}$} & \multirow[b]{2}{*}{ Sig. } \\
\hline & & B & Std. Error & & & \\
\hline 1 & (Constant) & 15.441 & 2.841 & & 5.436 & .000 \\
\hline & Lingkungan Kerja (X2) & .609 & .074 & .620 & 8.179 & .000 \\
\hline
\end{tabular}

a. Dependent Variable: Prestasi Kerja Karyawan (Y)

Berdasarkan hasil pengujian pada tabel di atas, diperoleh nilai thitung $>\mathrm{t}$ tabel atau $(8,129>1,982)$, dengan demikian hipotesis kedua yang diajukan bahwa terdapat pengaruh yang signifikan atara lingkungan kerja terhadap prestasi kerja 
karyawan diterima.

\section{Uji Hipotesis Simultan (Uji F)}

Pengujian hipotesis dengan uji $\mathrm{F}$ digunakan untuk mengetahui hipotesis simultan yang mana yang diterima.

Hipotesis ketiga Terdapat pengaruh yang signifikan antara motivasi kerja dan lingkungan kerja terhadap prestasi kerja karyawan.

Tabel 14. Hasil Uji Hipotesis Motivasi kerja dan Lingkungan kerja Terhadap

Prestasi kerja Karyawan.

\begin{tabular}{|c|c|c|c|c|c|c|}
\hline \multicolumn{7}{|c|}{ ANOVA $^{a}$} \\
\hline \multicolumn{2}{|c|}{ Model } & Sum of Squares & df & $\begin{array}{c}\text { Mean } \\
\text { Square }\end{array}$ & $\mathrm{F}$ & Sig. \\
\hline \multirow[t]{3}{*}{1} & Regression & 723.946 & 2 & 361.973 & 56.861 & $.000^{\mathrm{b}}$ \\
\hline & Residual & 674.788 & 106 & 6.366 & & \\
\hline & Total & 1398.734 & 108 & & & \\
\hline
\end{tabular}

a. Dependent Variable: Prestasi Kerja Karyawan (Y)

b. Predictors: (Constant), Lingkungan Kerja (X2), Motivasi Kerja (X1)

Berdasarkan hasil pengujian pada tabel di atas, diperoleh nilai $\mathrm{F}$ hitung $>\mathrm{F}$ tabel atau $(56,861>1,690)$, dengan demikian hipotesis ketiga yang diajukan bahwa terdapat pengaruh yang signifikan atara motivasi kerja dan lingkungan kerja terhadap prestasi kerja karyawan diterima.

\section{Pembahasan Hasil Penelitian}

\section{Pengaruh Motivasi Kerja Terhadap Prestasi Kerja Karyawan}

Motivasi kerja berpengaruh signifikan terhadap prestasi kerja karyawan dengan korelasi sebesar 0,649 atau memiliki hubungan yang kuat dengan kontribusi pengaruh sebesar $42,1 \%$. Pengujian hipotesis diperoleh nilai $t$ hitung $>\mathrm{t}$ tabel atau $(8,824>$ 1,982). Dengan demikian hipotesis pertama yang diajukan bahwa terdapat berpengaruh signifikan antara motivasi kerja terhadap prestasi kerja karyawan diterima.

\section{Pengaruh Lingkungan Kerja Terhadap Prestasi Kerja Karyawan}

Lingkungan kerja berpengaruh signifikan terhadap prestasi kerja karyawan dengan korelasi sebesar 0,620 atau memiliki hubungan yang kuat dengan kontribusi pengaruh sebesar $38,5 \%$. Pengujian hipotesis diperoleh nilai $t$ hitung $>t$ tabel atau $(8,129>1,982)$. Dengan demikian hipotesis kedua yang diajukan bahwa terdapat berpengaruh signifikan antara lingkungan kerja terhadap prestasi kerja karyawan diterima.

\section{Pengaruh Motivasi Kerja dan Lingkungan Kerja Terhadap Prestasi Kerja Karyawan}

Motivasi kerja dan lingkungan kerja berpengaruh signifikan terhadap prestasi kerja karyawan dengan diperoleh persamaan regresi $\mathrm{Y}=9,403+0,403 \mathrm{X} 1+0,368 \mathrm{X} 2$, nilai korelasi sebesar 0,719 atau memiliki hubungan yang kuat dengan kontribusi pengaruh sebesar 51,8\% sedangkan sisanya sebesar 48,2\% dipengaruhi faktor lain. Pengujian hipotesis diperoleh nilai F hitung $>\mathrm{F}$ tabel atau $(56,861>1,690)$. Dengan demikian hipotesis ketiga yang diajukan bahwa terdapat berpengaruh signifikan antara motivasi kerja dan lingkungan kerja terhadap prestasi kerja karyawan diterima. 


\section{KESIMPULAN DAN SARAN}

\section{Kesimpulan}

a. Motivasi kerja berpengaruh signifikan terhadap prestasi kerja karyawan dengan kontribusi pengaruh sebesar $42,1 \%$. Uji hipotesis diperoleh nilai t hitung $>\mathrm{t}$ tabel atau $(8,824>1,982)$.

b. Lingkungan kerja berpengaruh signifikan terhadap prestasi kerja karyawan dengan kontribusi pengaruh sebesar 38,5\%. Uji hipotesis diperoleh nilai t hitung $>\mathrm{t}$ tabel atau $(8,129>1,982)$.

c. Motivasi kerja dan lingkungan kerja berpengaruh signifikan terhadap prestasi kerja karyawan dengan kontribusi pengaruh sebesar 51,8\% sedangkan sisanya sebesar $48,2 \%$ dipengaruhi faktor lain. Uji hipotesis diperoleh nilai $\mathrm{F}$ hitung $>\mathrm{F}$ tabel atau $(56,861>1,690)$.

\section{Saran}

a. Perusahaan harus selalu memberikan semangat dan apresiasi yang layak untuk memastikan karyawan memiliki semangat kerja yang tinggi.

b. Perusahaan hendaknya melengkapi fasilitas atau sarana yang diperlukan oleh karyawan dalam rangka memperlancar pekerjaan mereka sehingga tidak tertunda lagi

c. Prestasi kerja perusahaan dapat ditingkatkan dengan memberdayakan karyawan dengan memberikan semangat, menegakkan peraturan yang baik dan pemberian fasilitas kerja yang lebih lengkap lagi.

\section{DAFTAR PUSTAKA}

A.A.Anwar Prabu Mangkunegara. 2011. Manajemen Sumber Daya Manusia. Perusahaan. Bandung PT: Remaja Rosda Karya

Ahmad Tohardi. 2015. Pemahaman Praktis Manajemen Sumber Daya Manusia, Universitas Tanjung Pura, Mandar Maju, Bandung

Andi Supangat. 2015. Statistik Dalam Kajian Deskriptif, Inferensi, dan. Nonparametrik. Jakarta : Kencana Prenada Media Group.

Arikunto, Suharsimi. 2014. Prosedur Penelitian : Suatu Pendekatan Praktik, Edisi. Revisi VI. Jakarta : PT Rineka Cipta

Byars, Llloyd L dan Rue, Leslie W. 2010. Human Resource Management, 8 edition

Ghozali, Imam, 2017. Aplikasi Analisis Multivariate Dengan Program SPSS, Edisi Keempat, Yogyakarta: Universitas Diponegoro

Hasibuan, Malayu S.P. 2014. Manajemen Sumber Daya Manusia. Penerbit: Jakarta,Bumi Aksara.

Hermawati, R., Sugiyarti, L., Handayani, R., Sunarsi, D., Alfiah, S., \& Maddinsyah, A. (2020). The Effect of Trilogy Leadership Style and Organization Culture on School Performance: Evidence form Indonesian Senior High School. PalArch's Journal of Archaeology of Egypt/Egyptology, 17(6), 8512-8537.

Kristianti, L. S., Affandi, A., Nurjaya, N., Sunarsi, D., \& Rozi, A. (2021). Pengaruh Motivasi Dan Disiplin Kerja Terhadap Kinerja Pegawai Pada Dinas Pariwisata Purwakarta. Jurnal Ilmiah PERKUSI, 1(1), 101-109.

Nawawi, Hadari, 2016, Manajemen Sumber Daya Manusia Untuk Bisnis yang Kompetitif. Yogyakarta: Gajah Mada University Press

Nitisemito, 2010, Manajemen Personalia. Jakarta: Ghalia Indonesia

Noe, R.A., Hollenbeck, J.R., Gerhart, B. and Wright, P.M. 2006. Human Resource Management: Gaining a competitive advantage, New York: McGraw Hill. 
Nurjaya, N., Affandi, A., Ilham, D., Jasmani, J., \& Sunarsi, D. (2021). Pengaruh Kompetensi Sumber Daya Manusia Dan Kemampuan Pemanfaatan Teknologi Terhadap Kinerja Aparatur Desa Pada Kantor Kepala Desa Di Kabupaten Gunungkidul, Yogyakarta. JENIUS (Jurnal Ilmiah Manajemen Sumber Daya Manusia), 4(3), 332-346.

Oei, Istijanto. 2014. Riset Sumber Daya Manusia. Gramedia Pustaka Utama. Edisi Revisi

Paeno, P. (2018). Pengaruh Motivasi dan Disiplin Terhadap Produktivitas Kerja Karyawan Pada PT. Agra Energi Indonesia. JENIUS (Jurnal Ilmiah Manajemen Sumber Daya Manusia), 1(3).

Pawar, A., Sudan, K., Satini, S., \& Sunarsi, D. (2020). Organizational Servant Leadership. International Journal of Educational Administration, Management, and Leadership, 63-76.

Rawi, R. D. P. (2017). Analisis Hubungan Motivasi Terhadap Kinerja Pegawai (Studi Kasus Pada Kantor Kecamatan Ruing Kabupaten Ngada Ntt). Jurnal Noken: IlmuIlmu Sosial, 2(2), 15-28.

Rivai, Veithzal dan Sagala, Ella Jauvani. 2003. Manajemen Sumber Daya Manusia untuk Perusahaan dari Teori ke Praktik. Jakarta: PT Raja Grafindo.

Rivai, Veithzal dan Sagala, Ella Jauvani. 2011. Manajemen Sumber Daya Manusia untuk Perusahaan dari Teori ke Praktik. Jakarta: PT Raja Grafindo.

Santoso, Singgih. 2015. Panduan Lengkap SPSS Versi 20. Jakarta: PT Elex Media Komputindo

Sedarmayanti. 2016. Sumber Daya Manusia dan Produktivitas Kerja. Bandung: Mandar Maju

Siagian, P Sondang. 2012. Manajemen Sumber Daya Manusia.Penerbit: Jakarta, Bumi Aksara.

Sudiarto, S. (2018). Membangun Motivasi Kerja Guru Dalam Menyiapkan Sumber Daya Manusia Indonesia Yang Berkualitas (Analisis Teori Motivasi Abraham Maslow Di SMK Negeri 57 Jakarta). JENIUS (Jurnal Ilmiah Manajemen Sumber Daya Manusia), 1(3).

Sudjana. 2014. Metode Statistika, Bandung: Penerbit Tarsito

Sugiyono. 2017. Metode Penelitian Kuantitatif, Kualitatif, dan R\&D. Penerbit: Bandung,Alfabeta

Sunyoto, Danang, 2012. Manajemen Sumber Daya Manusia. Yogyakarta: Cet. 1, CAPS (Center For Academic Publising Service).

Sunyoto, Danang, 2013. Manajemen Sumber Daya Manusia. Yogyakarta: Cet. 1, CAPS (Center For Academic Publising Service).

Sutrisno. 2016. Manajemen Sumber Daya Manusia. Jakarta: Kencana.

Wibowo. 2014. Manajemen Kinerja. Edisi Keempat . Jakarta : Rajawali Pers.

Winardi, 2016, Manajemen Perilaku Organisasi, Edisi Revisi, Jakarta, Kencana Prenada Media Group. 